\title{
Montmorillonite colloid plates with adsorbed cytochrome $c$ : in vitro cytotoxic effect on colon cancer cell culture
}

\author{
Svetlana H. Hristova ${ }^{1}$ and Alexandar M. Zhivkov² ${ }^{2^{*}}$
}

\author{
${ }^{*}$ Correspondence: \\ zhivkov_ipc@doctor.bg \\ ${ }^{2}$ Rostislaw Kaishew" Institute \\ of Physical Chemistry, \\ Bulgarian Academy \\ of Sciences (BAS), Acad. \\ G. Bonchev Str., bl. 11, \\ 1113 Sofia, Bulgaria \\ Full list of author information \\ is available at the end of the \\ article
}

\begin{abstract}
Background: The apoptosis (a cascade of biochemical reactions leading to suicide of damaged biological cells) is blocked in the cancer cells because of impossibility of cytochrome $c$ (cytC) go out from the mitochondria. However, the apoptosis can be started by introducing of exogenous cytC into cytoplasm using colloid particles as a protein carrier due to ability of the cancer cells to phagocytize extracellular particles with submicron size.
\end{abstract}

Results: The clay mineral montmorillonite (MM) were used to prepare aqueous suspension of protein/mineral composite particles by electrostatic adsorption of the positively charged cytC globules on the negatively charged MM colloid plates, and then added to colon cancel culture. The results shows out that separately cytC and MM have no effect but the composite cytC-MM particles kill 95\% of the cancer cells after $96 \mathrm{~h}$ treatment using equine cytC which is $97 \%$ structurally identical with the human cytC. To reach this high cytotoxicity we have formulated requirements to: (a) bare colloid particles (electric charge, form and size), (b) conditions for protein adsorption (concentrations, pH, ionic strength), and (c) suspension with the composite particles (positive total charge and optimal concentration). Due to satisfying these requirements we have reached cytotoxicity which is $1 / 3$ higher than the reached by other authors using different artificial particles. The cytotoxicity rapidly increases with concentration of the cytC-MM particles but further it shows tendency to saturation.

Methods: The optimal pH 6.5 and the $10: 3 \mathrm{mg} / \mathrm{mg}$ cytC/MM concentration ratio at adsorption were found out by employing computer (protein electrostatics) and physicochemical methods (microelectrophoresis and colloid electrooptics) to prepare cytCMM suspension. The anticancer capability of cytC-MM nanoplates were investigated using cell culture of metastasizing colon cancer.

Conclusion: The in vitro experiments with colon cancer cell culture disclose that cytC-MM composite particles have potential for application in anticancer therapy of superficial neoplasms of the skin and the alimentary system (mouth cavity, esophagus, stomach, jejunum and colon).

Keywords: Cytochrome c, Montmorillonite, Electric light scattering, Microelectrophoresis, Protein electrostatics, Cytotoxicity, Cancer cell culture, Nanoparticles author(s) and the source, provide a link to the Creative Commons licence, and indicate if changes were made. The images or other third party material in this article are included in the article's Creative Commons licence, unless indicated otherwise in a credit line to the material. If material is not included in the article's Creative Commons licence and your intended use is not permitted by statutory regulation or exceeds the permitted use, you will need to obtain permission directly from the copyright holder. To view a copy of this licence, visit http:// creativecommons.org/licenses/by/4.0/. The Creative Commons Public Domain Dedication waiver (http://creativecommons.org/publi cdomain/zero/1.0/) applies to the data made available in this article, unless otherwise stated in a credit line to the data. 


\section{Introduction}

Cytochrome $c$ (cytC) is a water-soluble haem-containing globular protein (104 aminoacid residues, $12.4 \mathrm{~kg} / \mathrm{mol}$ molecular mass, $3 \mathrm{~nm}$ size) associated to the electrontransport macromolecule complex of the internal mitochondrial membrane, where it works as $\mathrm{Fe}^{2+} / \mathrm{Fe}^{3+}$ electron carrier in the normal eukaryotic cells. Besides, in the process of apoptosis (a programmed suicide of damaged or degenerate cells) cytC enter into the cytoplasm (Green and Reed 1998), and that starts irreversibly a multistage cascade of biochemical reactions which results in destroying of DNA and finally to death of the defective cell (Jiang and Wang 2004). When the process of apoptosis is disturbed, various diseases arise as cancer, neurodegenerative, autoimmune, etc.

In case of cancer cells the mitochondrial oxygen metabolism is replaced by anaerobic utilization of glucose with accumulation of lactate in the cytoplasm (Warburg effect) (Warburg et al. 1926; Vander Heiden et al. 2009; Gatenby and Gillies 2004), and that leads to impossibility of cytC to go out from the mitochondria; as result the apoptosis is blocked, and a resistance appears to chemotherapeutics that should start this process (Gogvadze et al. 2009; Shannon et al. 2003; Bhattacharya et al. 2016). The direct application of cytC solution is ineffective because of impossibility of the hydrophilic globular proteins to penetrate through the hydrophobic bilayer of the cytoplasmic membrane, as it was proved out in our experiments. The difficulty can be overcome by a microinjection of exogenous cytC into the cytoplasm, that starts irreversibly the apoptosis in cancer cells (Zhivotovsky et al. 1998; Kandasamy et al. 2003; Vaughn and Deshmukh 2008); but this laboratory technique of injection into single cells is unadaptable to clinical therapy.

Another way for introduction of cytC is based on the ability of cancer cells to phagocytize extracellular particles with (sub)micron size; that allows using colloid particles as a protein carrier. A rule in pharmacology and medicine is that intravenous injection of particles with colloid size (indicated by the turbidity of their suspension), except liposomes, is forbidden owing to possible thrombosis, but they can be applied for peroral treatment of superficial neoplasms of the alimentary system or directly in the case of the skin. In some reports authors explore this possibility using various sophisticated artificial nanoparticles with adsorbed cytC (Malekigorji et al. 2014; Méndez et al. 2014; Santra et al. 2010; Ng et al. 2013); the results show out about $60 \%$ cytotoxicity. Probably, this relatively low efficiency is the reason that this perspective direction of investigations has not been extended with more suitable nano- and colloid particles. We have reached 95\% cytotoxicity using mineral particles with simple form, suited size and optimal conditions for cytC adsorption on their surface, which were selected employing physicochemical and computer methods; the preliminary results have been published in Ref. (Hristova and Zhivkov 2019a).

To prepare suspension of bearing cytC composite colloid particles with maximal cytotoxic effect we have formulated the following requirements to the particles and experimental conditions: (a) the electric charge of the bare colloid particles must be opposite by sign to that of cytC to condition electrostatic adsorption of its globules; (b) the particle size should be optimal to allow easy forming of intracell vesicle by bending of the cytoplasmic membrane; (c) the plane form of the nanoparticles is preferred, assuming that it facilitates their adsorption on the cell membrane due to bigger area of contact; (d, e) at adsorption of cytC globules on the colloid particles (d) $\mathrm{pH}$ must be chosen so that 
cytC globules obtain net electric charge which is opposite to that of the particle surface to condition electrostatic adsorption, and (e) the ionic strength should be retained as low as possible to have stronger electrostatic protein/surface attraction and sufficient particle/particle repulsion; (f) the total electric charge of the composite cytC-nanoparticles must be positive to condition electrostatic adsorption on the negatively charged cytoplasmic membrane; (g) the cytC adsorption on the particles must be saturated (maximal protein density on the surface) to introduce maximum cytC globules at phagocytosis of one cytC-particle; $(h, i)$ the concentration of bare particles should be sufficiently low to avoid aggregation and by that to retain optimal size for phagocytosis of the composite cytC-particles: (h) at their preparing by adsorption of cytC, and (i) in isotonic suspension with $0.15 \mathrm{M} \mathrm{NaCl}$ (before and after adding to the cell culture); and (j) the final concentration of the composite cytC-particles should be sufficiently high to reach high cytotoxicity.

To meet the first three conditions we have chosen lamellar particles from the nanolayered alumosilicate clay mineral montmorillonite (MM), because: (a) $\mathrm{MM}$ has $\mathrm{pH}$ independent negative charge caused by partial substitution of extraneous atoms in the crystal lattice with lower valency ones: $\mathrm{Zn}^{2+}$ and $\mathrm{Fe}^{2+}$ instead $\mathrm{Al}^{3+}$ in the inner sublayer and $\mathrm{Al}^{3+}$ instead $\mathrm{Si}^{4+}$ in the two outer sublayers (Murray 2006; Schoonheydt et al. 2018); (b) the size (submicrometric to some micrometers) of MM plates covers the 0.2$0.5 \mu \mathrm{m}$ range which is optimal for phagocytosis by colorectal cancer cells (Cortez et al. 2007; Win and Feng 2005); a fraction with required size can be obtained by centrifugation (Hristova and Zhivkov 2015); (c) MM particles have plate-lake form due to the planar symmetric crystal structure (three sheet sublayers: central AlO and two lateral $\mathrm{SiO}$ ) of a lamella with $0.9 \mathrm{~nm}$ thickness. The thickness of natural MM plates (pack of lamellae) diminishes from $20 \mathrm{~nm}$ to 1-2 nm (Krupskaya et al. 2017) at treatment with inorganic acids because of cleaving of the multilamellar packs down to monolamellae (Nadeau 1985) due to increased electrostatic repulsion as a result of replacement of $\mathrm{Ca}^{2+}$ with $\mathrm{Na}^{+}$in the gaps between the lamellae (Whalley and Mullins 1991; Shainberg and Otoh 1968); that grows the surface/mass ratio (about $250 \mathrm{~m}^{2} / \mathrm{g}$ of Na-MM used in our research), and, respectively, leads to high protein-adsorption capability. In addition, MM has chemical inertness, good biocompatibility and non-toxicity proven by hematological, biochemical and histopathological analyses in rat (Khatoon et al. 2020; Leporatti et al. 2020; Liao et al. 2020); that allows its using in medicine and pharmacy as carrier in drug delivery systems, gene therapy and tissue engineering (Persano et al. 2021; Yu et al. 2015; Karataş et al. 2017; Jayrajsinh et al. 2017; Jafarbeglou et al. 2016; El-Hamshary et al. 2019), and it is also widely used in cosmetics and as nutritional supplement.

The electric charge of a protein macromolecule in aqueous solution is $\mathrm{pH}$-dependent owing to protonation/deprotonation of the carboxylic $\left(\mathrm{COO}^{-} \leftrightarrow \mathrm{COOH}\right)$ and amino $\left(\mathrm{NH}_{2} \leftrightarrow \mathrm{NH}_{3}^{+}\right)$groups of the aminoacid residues. The degree of dissociation depends on the local $\mathrm{H}^{+}$-concentration which is determined by the electric field in its vicinity and $\mathrm{pH}$ in the bulk; therefore, both the dissociation constant $\mathrm{pK}_{\mathrm{a}}$ of every individual group of cytC globule (Hristova et al. 2009) and its isoelectric point (zero net charge) (Hristova and Zhivkov 2019b, c) depend on its 3D-structure, besides the aminoacid content and sequence of the polypeptide chain. The possibility to alter the ionization of the carboxylic groups allows satisfying the condition (d) by choosing $\mathrm{pH}$ at which the net charge 
of cytC globules is positive to determine their electrostatic adsorption on the negatively charged MM plates. It was found out experimentally that cytC globule retain its native conformation in wide pH 3-12 range (Dickerson and Timkovich 1975; Paul 1948) and being adsorbed on solid dielectric surfaces (Maeda et al. 1995; Lee et al. 2005). The very stable 3D-structure of cytC is determined by the presence of haem cycle which plays a role of skeleton on which a short alpha-helix is coiled and covalently bound. In addition, cytC isolated from equine heart is stable to both low $\mathrm{pH}$ and stomach proteolytic enzymes (trypsin, chymotrypsin, elastase): the results revels that for $4 \mathrm{~h}$ treatment only $20 \%$ of cytC macromolecules are destroyed (Endo et al. 1985); that allows using of cytCMM particles for treatment of neoplasms in the alimentary tract.

The biological membranes are negatively charged due to predominance of acid lipids which content is about 10-20\% (Gennis 1989). The electric charge on the two surfaces of the cytoplasmic membrane is asymmetric, because the charged lipids and the membrane proteins are dissymmetrically disposed. The membrane asymmetry diminishes at the first stages of the apoptosis when it appears transition of phosphatidylserine molecules from the inner to the outer surface. In the case of cancer cells the charge of the external surface is even more negative because of increased content of phosphatidylserine: about $20 \%$, instead of $5 \%$ in normal cells (Sharma et al. 2018). Therefore, the condition (f) (which requires that cytC-MM particles must be positively charged) is obligatory to condition electrostatic adsorption on the cell surface. That means that the negative MM plates should be recharged to obtain positive total charge by overequivalent adsorption of cytC.

According the conditions ( $\mathrm{d}, \mathrm{f}, \mathrm{g}$ ), to prepare cytC-MM particles with maximal cytotoxicity we have employed computer (protein electrostatics) and experimental techniques (microelectrophoresis and electric light scattering) to found out optimal conditions: $\mathrm{pH}$ and cytC/MM concentration ratio. To investigate in vivo the anticancer capability of cytC-MM composite particles we have used cell culture of metastasizing colon cancer. This kind of cancer was chosen considering the surface localization of its neoplasms; that allows supposing that cytC-MM can be used for treatment of superficial neoplasm of the skin, mouth cavity, esophagus, stomach, duodenum, jejunum, colon and colorectal, which allow local treatment.

Our preliminary results have shown that incubation of a colon cancer cell culture with cytC-MM suspension causes cytotoxic effect which growth with the time (Hristova and Zhivkov 2019a); an imperfection of the experiments was that the cytC-MM particle concentration had been chosen at random. In the present research we investigate dependence of the cytotoxicity on the concentration of cytC-MM composite particles at fixed cytC/MM ratio. The new results cover the older ones and confirm the high potential of cytC-MM composite particles for application in anticancer therapy.

\section{Materials and methods}

\section{Computer techniques}

The computer analyses have been performed by the programs: (a) Propka, Bluues and PHEMTO (Kantardjiev and Atanasov 2009) (protein electrostatics), (b) SuperPose (macromolecular alignment), and VMD simulator (visualization), using 3D atom coordinates of 1 hrc crystallographic structure of equine cytC taken from Protein data bank. 


\section{Sample preparing}

Montmorillonite powder K10 (Sigma-Aldrich, 220-270 m²/g) was suspended in triple-distilled water, 5 min sonicated by ultrasonic disintegrator (Techpan, Poland) at $20 \mathrm{kHz}$, and suspension of MM particles with mean size $0.46 \mu \mathrm{m}$ and small polydispersity was isolated by fourfold centrifuging at: $300 \times g, 600 \times g, 1300 \times g$, and $2000 \times g$ for 7 min every and taking the supernatant, as it is described in Ref. (Hristova and Zhivkov 2015).

Into the obtained MM suspension it was slowly poured an aqueous solution of ferric equine heart cytC (Calbiochem) with $\mathrm{pH} 6$ at stirring for 30 min with final concentration $3 \mathrm{mg} / \mathrm{L} \mathrm{MM}$ and $0.1-90 \mathrm{mg} / \mathrm{L}$ cytC (in the experiments studying the protein adsorption, "Aqueous cytC-MM suspension" section). To study the viability of the cell cultures were used 3-60 mg/L MM suspension, 10-200 mg/L cytC solution, and composite cytC-MM particles with 3-60 mg/L MM and 10-200 mg/L cytC at 10:3 mg/mg cytC/MM ratio of all concentrations ("Viability at presence of cytC, MM and cytCMM" section). In case of the concentration dependence ("Concentration dependence of cytC-MM cytotoxicity" section) the initial MM concentration was 20 times higher $(0.06 \mathrm{~g} / \mathrm{L} \mathrm{MM})$; the cytC solution was slowly poured into the diluted stock MM suspension at retaining 10:3 protein/particles ratio of the weight concentrations in the same range (3-60 $\mathrm{mg} / \mathrm{L} \mathrm{MM}$ and 10-200 $\mathrm{mg} / \mathrm{L} \mathrm{cytC}$ ). In the experiments with the tumor cells $\mathrm{NaCl}$ with $0.15 \mathrm{M}$ final concentration was added to the cytC-MM suspension immediately before it pouring to the cell culture. In all experiments (physicochemical and biological) triple-distilled water was used.

\section{Microelectrophoresis}

The electrophoretic mobility $\mu=v / E$ was measured by Mark II apparatus with darkfield microscope (Rank Brothers, UK) as mean velocity $v$ of $20+20$ cytC-MM particles migrating in direct electric field with strength $E=16 \mathrm{~V} / \mathrm{cm}$ at reversing of the field direction for every particle and at focusing in the two stationary planes (where the electroosmotic flow is zero) of the used closed vertical flat electrophoretic cell. The electrokinetic potential $\zeta$ was calculated from the measured mobility $\mu$ in aqueous medium with viscosity $\eta$ and dielectric permittivity $\varepsilon_{0} \varepsilon$ employing the Smoluchowski-Hückel-Henry's equation (Dukhin and Deryagin 1976; Hunter 1981):

$$
\mu=\left(\varepsilon \varepsilon_{0} / \eta\right) f(a / \delta) \zeta,
$$

where Henry's function $f(a / \delta)=0.81$ at $a / \delta \approx 7.5$ was calculated for spherical dielectric particle with diameter $2 a=0.46 \mu \mathrm{m}$ in medium with ionic strength $0.1 \mathrm{mmol} / \mathrm{L}$, where the thickness of its electric double layer is $\delta \approx 30.5 \mathrm{~nm}$.

\section{Electric light scattering}

The method of electric light scattering (Stoylov 1991), based on the electrooptical effect (EOE) $\Delta I=I_{\mathrm{E}}-I_{0}$ (alteration of the scattering intensity $I$, respectively, at presence $I_{\mathrm{E}}$ and absence $I_{0}$ of electric field) which appears at orientation of the colloid particles under action of the electric field applied in a suspension by two parallel metal electrodes, was used to check for possible aggregation and to determine the size $B$ 
of $\mathrm{MM}$ and cytC-MM particles by measuring the relaxation time $\tau_{0}$ for which the momentary value $\Delta I_{t}$ decreases with the time $t$ down to $37 \%$ after field switching off, starting from its steady-state value $\Delta I_{\mathrm{s}}$; for monodisperse suspension:

$$
\Delta I_{t}=\Delta I_{\mathrm{s}} \exp \left(-t / \tau_{0}\right)
$$

where $\tau_{0}=1 / 6 D_{\mathrm{r}}$ is defined by the rotational diffusion coefficient $D_{\mathrm{r}} \sim k T / \eta B^{3}$ determined by the thermal energy $k T$ and the particle geometry (the form and size $B$ ) in medium with viscosity $\eta$ at temperature $T$ reflecting the surface friction in the process of particle disorientation. For disk-like particles with diameter $B$ :

$$
\tau_{0}=(2 \eta / 9 \mathrm{kT}) B^{3} ;
$$

$\tau_{0}=59 B^{3}$ in aqueous medium at $20^{\circ} \mathrm{C}$ when the relaxation time $\tau_{0}[\mathrm{~ms}]$ and the diameter $B[\mu \mathrm{m}]$ are given in milliseconds and micrometers, respectively (Zhivkov 2007). Due to the cubic dependence $\tau_{0} \sim B^{3}$ the method is very sensitive to the particle size; besides, EOE decay $\Delta I_{t}(t)$ is polyexponential in case of polydisperse suspension (Spartakov et al. 2007). The $I_{0}$ and $\Delta I$ were measured at scattering angle $\theta=90^{\circ}$ by computerized home-made apparatus (Hristova and Zhivkov 2015) using electrooptical cell with interelectrode distance $2.6 \mathrm{~mm}$, to which it was applied sinusoidal voltage $140 \mathrm{~V}$ with frequency $5 \mathrm{kHz}$, generated by Wavetek-185 functional generator and amplified by Krohn-Hite-7500 amplifier.

\section{Cancer cell cultures}

A culture of metastatic colorectal adenocarcinoma cell line isolated from lymph node (ATCC ${ }^{\circledR}$ CCL-227) with $1 \times 10^{4}$ cells/well initial concentration was used after 3 day preliminary cultivation in 96-well plate with L-15 culture media and added solutions of $10 \%$ fetal bovine serum albumin and 1\% antibiotic-antimycotic (Gibco). After triple washing by $0.15 \mathrm{M} \mathrm{NaCl}$, to each well was added $0.1 \mathrm{~mL}$ of cytC-MM suspension, cytC solution, $\mathrm{MM}$ suspension, or $0.15 \mathrm{M} \mathrm{NaCl}$. After 24, 48 and $96 \mathrm{~h}$ treatment (and additional triple washing) to each well were added $50 \mu \mathrm{L} 1 \%$ solution of human serum albumin in PBS buffer and $50 \mu \mathrm{M}$ Trypan Blue with $2 \%$ final concentration. After 3 min treatment, the dye was washed, and three fields of the culture were photographed under inverse microscope: $N=220$ cells at objective $10 \times$ or $N=1280$ at $5 \times$. The death (blue colored) and the vital (colorless) cells (Fig. 1) were counted after the experiment: the dead in the check sample or the vital at high cytotoxicity (because a part of the death cells are destroyed). The cytotoxicity $\left(N_{\mathrm{d}} / N_{\mathrm{vit}}\right) \times 100$ was calculated as cell ratio of threefold numbers of the dead $\left(3 \times N_{\mathrm{d}}\right)$ to vital $\left(3 \times N_{\text {vit }}\right)$; the viability is determined as reverse quantity of the cytotoxicity; the vital cells number $3 \times N_{\text {vit }}=660$ in the check sample was defined as $100 \%$ viability.

\section{Results}

\section{$\mathrm{pH}$-dependent charge of cytC}

The averaged dependences $\mathrm{pK}_{\mathrm{a}}(\mathrm{pH})$ of all acidic and basic groups of a cytC globule on the bulk $\mathrm{pH}$ (calculated by protein electrostatics using the crystallographic coordinates) show out: zero net charge $(n z=0)$ at $\mathrm{pH} 10.1$, quasiplateau at $\mathrm{pH} 5.6-8.5$ and increasing positive charge in the acid range $\mathrm{pH} 2-5$ (Fig. 2). The $\mathrm{pH}$-dependence of the net 


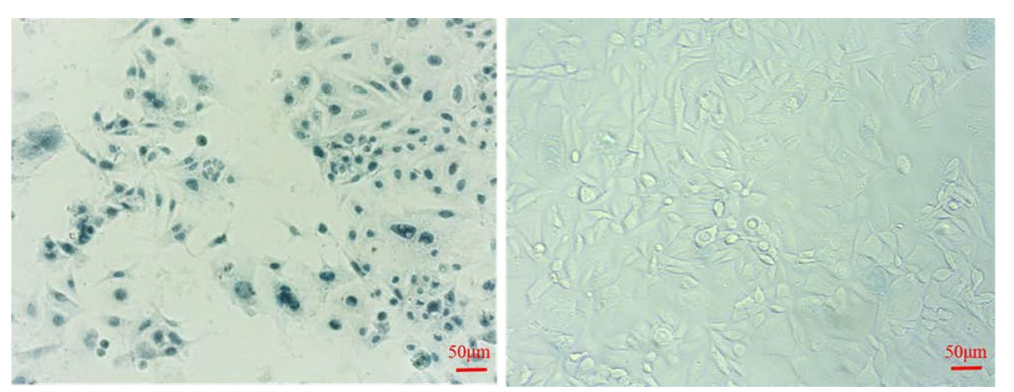

Fig. 1 Coloured by Trypan Blue colon cancer cultures after $96 \mathrm{~h}$ incubation in isotonic medium with: a cytC-MM suspension containing $200 \mathrm{mg} / \mathrm{L} \mathrm{cytC}$ and $60 \mathrm{mg} / \mathrm{L}$ (the left photography), and b $0.15 \mathrm{M} \mathrm{NaCl}$ solution (the right photography)

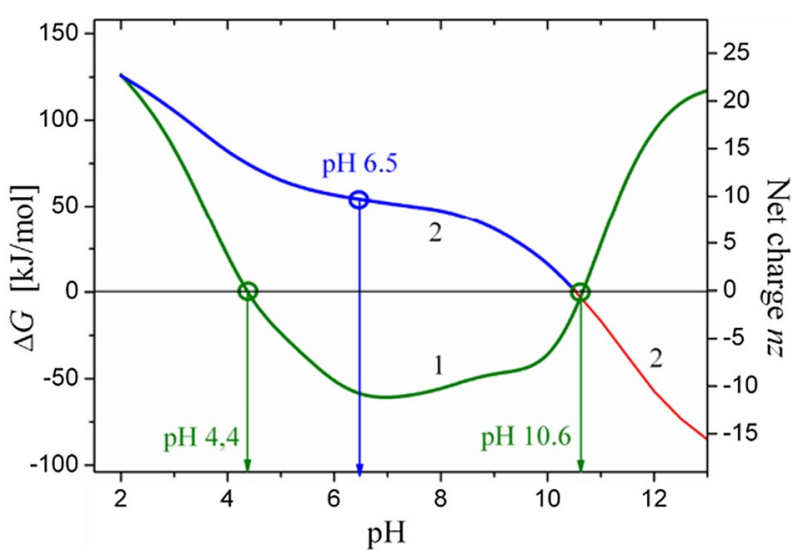

Fig. 2 Computed pH-dependences of the electrostatic component of the Gibbs free energy $\Delta G(p H)$ (left ordinate, curve 1, the two open circles indicate $\Delta G=0$ ) and the net charge $n z(p H)$ (right ordinate, curve 2, the two open circles indicate the used in the experiments $\mathrm{pH} 6.5$ and the isoelectric point $n z=0$ at pH 10.6) of free equine cytC globule in aqueous medium. The two parts of the curve $n z(\mathrm{pH})$ are colored according to the net charge sign: positive (blue) and negative (red)

charge suggests that the protein/mineral electrostatic attraction between cytC globules and $\mathrm{MM}$ surface is stronger at $\mathrm{pH} \leq 5$ due to the higher positive net charge.

The intramolecular electrostatic balance of a protein globule can be presented as electrostatic component of the Gibbs free energy: its negative value predicts stable conformation of cytC in the range $\mathrm{pH} 4.4-10.6$. In the range $\mathrm{pH}<4$ the cytC macromolecule should lose its native 3D conformation, because the negative charge of the carboxylic groups disappears and the uncompensated repulsion of the positively charged amino groups expands the globule and then unfolds the polypeptide chain. However, the contribution of the hydrogen bonds and Van-der-Waals forces expend the actual pH-range of stability to $\mathrm{pH}$ 3-12 for cytC in solution (Dickerson and Timkovich 1975).

According the conditions (d) and (e) (formulated in "Introduction") we have chosen $\mathrm{pH} 6.5$ as a most appropriate for adsorption of cytC on the negatively charged MM plates; that allows, besides $\mathrm{pH}$-stability of cytC conformation (determined by the deep energy trough, Fig. 2), to avoid using of acid or buffers and by that to keep up the ionic strength on minimal level, where the electrostatic interactions (globule/plate attraction and globule/globule repulsion) are strong enough for both the adsorption (Hristova and 
Zhivkov 2015) and to avoid protein aggregation in the bulk. Besides, the moderate positive charge of cytC globules at $\mathrm{pH} 6.5$ allows forming of more dense protein monolayer (condition g) due to less stronger electrostatic repulsion between the globules adsorbed on the solid surface.

\section{Aqueous cytC-MM suspension}

According the conditions $(\mathrm{f}-\mathrm{j})$, at preparing of cytC-MM suspension it is required choosing of cytC/MM ratio and optimal concentrations of the composite cytC-MM particles, which should be concurrently enough high to reach high cytotoxicity and sufficiently low to avoid their aggregation.

To meet the conditions ( $\mathrm{f}$ ) and (g) (positive total charge of cytC-MM particles and maximal number of cytC globules adsorbed on one MM particle), it is need to estimate the degree of adsorption at given protein concentration $C_{\mathrm{cyt}}$, a criterion for which is the total charge of the composite cytC-MM particles; for that we use the electrokinetic potential $\zeta$ calculated from the measured electrophoretic mobility $\mu$ by Eq. (1). The concentration dependence $\zeta\left(C_{\text {cyt }}\right)$ (Fig. 3) show out that the negative charge of the bare MM plates rapidly decreases (by absolute value) even at very low cytC concentration because of adsorption of cytC globules (positively charged at pH 6.5, Fig. 1); the fact confirms the expectation of electrostatic type of adsorption.

The isoelectric point $(\mu=0, \zeta=0)$ of cytC-MM particles appears at $3 \mathrm{mg} / \mathrm{L}$ cytC in $3 \mathrm{mg} / \mathrm{L}$ MM suspension (1:1 protein/particles ratio); further increasing of $C_{\text {cyt }}$ leads to overequivalent adsorption manifested by change of $\zeta$ sign from negative to positive (Fig. 3). As optimal concentrations we have chosen $10 \mathrm{mg} / \mathrm{L}$ cytC and $3 \mathrm{mg} / \mathrm{L} \mathrm{MM}$ (the beginning of the plateau, 10:3 ratio), at which cytC-MM particles are almost completely recharged but the concentration of free (non-adsorbed) cytC globules in the bulk remains minimal. That allows satisfying the conditions (g) and (f): maximum adsorbed

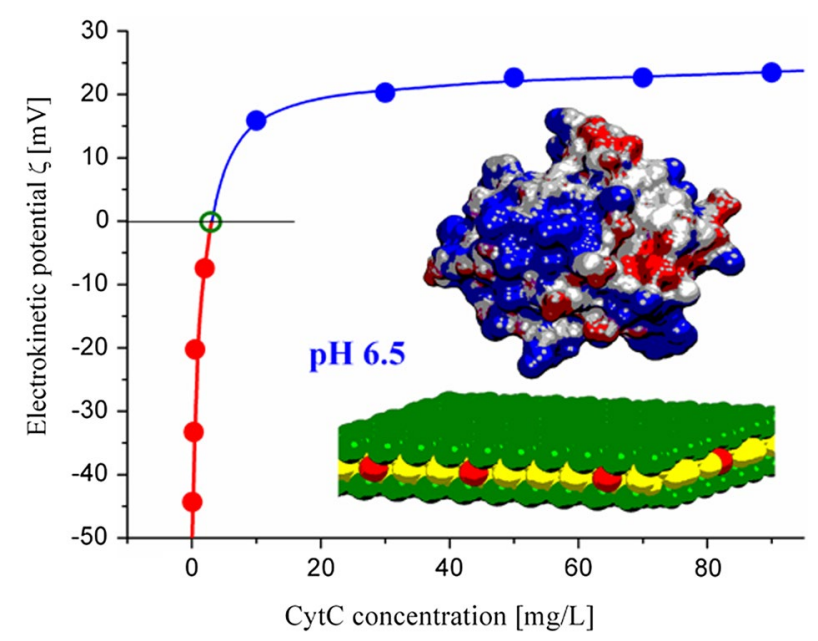

Fig. 3 Dependence of the electrokinetic potential $\zeta$ of cytC-MM particles on the cytC concentration $C_{\text {cyt }}$ in suspension with $3 \mathrm{mg} / \mathrm{L} \mathrm{MM}$ and $0.1-90 \mathrm{mg} / \mathrm{L} \mathrm{cytC}$ at pH 6.5. Inset: models of MM plate and cytC globule at $\mathrm{pH}$ 6.5; the surface potential of cytC globule and the substitution atoms in the MM crystal are coloured in blue (positive), red (negative) and white (neutral) or green (the two lateral SiO) and yellow (the central AlO) sublayer 
cytC globules per MM plate and positive total charge which facilitate electrostatic adsorption of cytC-MM particles on the negatively charged cytoplasmic membrane. The estimation reveals that at saturated adsorption on $\mathrm{MM}$ surface there are 8-9 cytC globules per $100 \mathrm{~nm}^{2}$ area (Hristova 2019), or about 14,370 globules on one MM plate with average diameter $464 \mathrm{~nm}$; the MM size was calculated by Eq. (3) from the electrooptically measured relaxation time $\tau_{0}=5.9 \mathrm{~ms}$.

Although the optimal 10:3 cytC/MM ratio provide saturated adsorption at which the electrostatic potential of the already recharged cytC-MM particles is enough strong, a possibility for aggregation appears in the process of adsorption when of the single particles pass through state of transient zero chatge (although the cytC concentration is above that of the isoelectric point, Fig. 3). The aggregation can be avoided by minimizing the MM concentration but at the same time it should be enough high to reach maximal cytotoxicity, i.e., to meet the opposite conditions (h) and (j). To avoid the aggregation, we have found empirically an optimal rate of adding of cytC solution to the MM suspension: not at ones (evading very high local protein concentration) but sufficiently quickly to allow recharging of the single particles before they have time to aggregate. The last is possible due to very different translational velocity: very fast in case of free protein globules and much slower for colloid particles; the difference reflects the coefficients of translational diffusion (inversely proportional to the size) of $3 \mathrm{~nm}$ cytC globules and $0.5 \mu \mathrm{m}$ MM particles. The suspension was tested for possible aggregation by measuring the relaxation time $\tau_{0}$ from the relaxation curve $\Delta I_{t}(t)$ (Eq. 2) at complete cytC adsorption; as optimal it was chosen particle concentration $3 \mathrm{mg} / \mathrm{L} \mathrm{MM}$. The electrooptical measurements have shown that at saturated adsorption $(10-100 \mathrm{mg} / \mathrm{L}$ cytC in $3 \mathrm{mg} / \mathrm{L}$ MM suspension) cytC-MM particles have $\tau_{0}=7.5 \mathrm{~ms}$ which does not increases with the time, and the relaxation curve $\Delta I_{t}(t)$ retains its form; the both facts prove absence of aggregation (Hristova and Zhivkov 2015).

\section{Viability at presence of cytC, MM and cytC-MM}

The viability of cancer cell culture was tested with suspensions of MM nanoplates, solutions of cytC protein, and suspension of composite cytC-MM particles (all in $0.15 \mathrm{M}$ $\mathrm{NaCl}$ isotonic conditions) on 24, 48 and $96 \mathrm{~h}$ after adding to the culture; Figs. 4 and 5 show results on the first and fourth days of the treatment. The cell viability practically does not depend upon the separately added MM suspension and cytC solution, but the cells decays at presence of cytC-MM particles: the living cells share remains $25 \%$ on the 48th hour and only $6 \%$ on the 96th hour. The lack of effect of cytC can be explained with impossibility of its $3 \mathrm{~nm}$ hydrophilic globules to penetrate through the hydrophobic bilayer of the cytoplasmic membrane. In case of the MM suspension two reasons are possible: (a) MM plates remains out of the cancer cells, because their adsorption on the membrane surface is hampered owing to the electrostatic repulsion (both the bare MM particles and the membrane are negatively charged); (b) the MM plates are phagocytized but have no effect.

In difference of their components, the composite cytC-MM particle shows out strong cytotoxic effect which reaches $94 \%$ after $96 \mathrm{~h}$ treatment. We explain the obtained high cytotoxicity with: (a) the electrostatically conditioned adsorption of the positive charged cytC-MM plates on the negative cytoplasmic membrane; (b) the optimal $(0.5 \mu \mathrm{m})$ size 


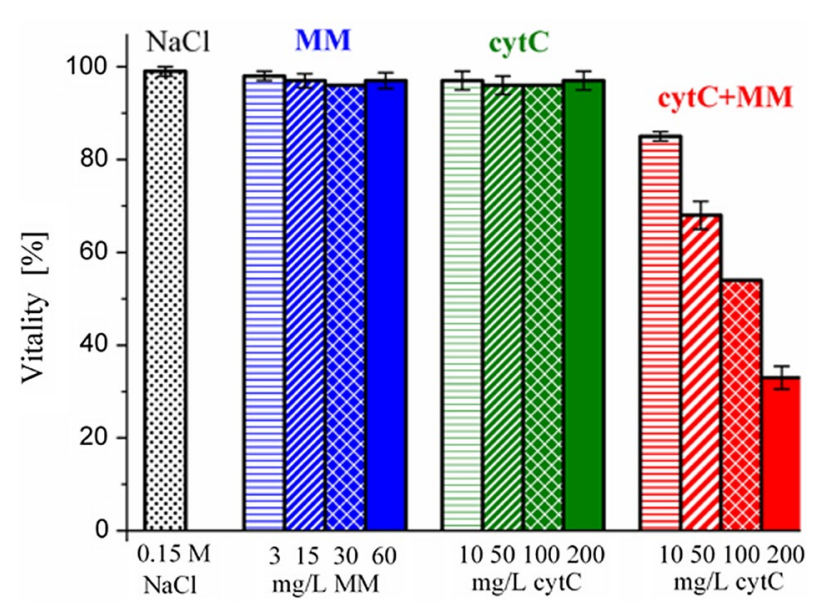

Fig. 4 Viability of colon cancer cell cultures on 24th hour after pour of: $0.15 \mathrm{M} \mathrm{NaCl}$ solution (check sample); MM suspension (3, 15, 30, 60 mg/L); CytC solution (10, 50, 100, $200 \mathrm{mg} / \mathrm{L}$ ) and cytC-MM suspension (10-200 mg/L cytC in 3-60 mg/L MM at constant 10:3 mg/mg cytC/MM concentration ratio). In all samples the medium is aqueous $0.15 \mathrm{M} \mathrm{NaCl}$

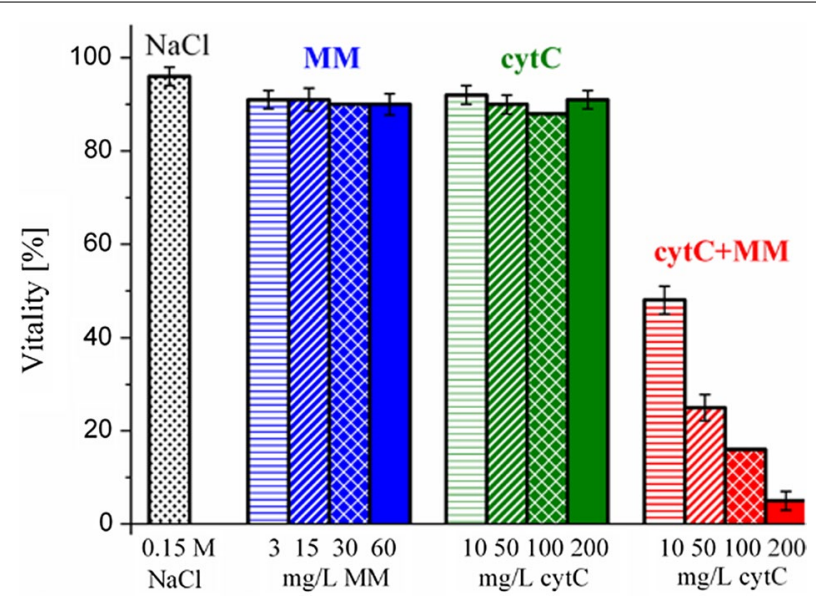

Fig. 5 Viability of similar cancer cell cultures on $96^{\text {th }}$ hours after beginning of treatment at the same concentrations as that in Fig. 4

the of cytC-MM particles allowing effective uptake; and (c) cytC macromolecules initiate the process of apoptosis which result in cell dead.

\section{Concentration dependence of cytC-MM cytotoxicity}

The cytotoxic effect should depend on the concentrations of cytC, MM, and the composite cytC-MM particles. The protein concentration dependence ("Aqueous cytCMM suspension" section) allows choosing of $10: 3 \mathrm{mg} / \mathrm{mg}$ cytC/MM ratio as optimal for preparing of the composite particles, and the dependence on the cytC-MM concentration in the cell culture allows reaching high effect/dose ratio. The cytotoxicity should increases with cytC-MM concentration but it is possible that above some optimal concentration the effect could decreases because of aggregation which enlarges 


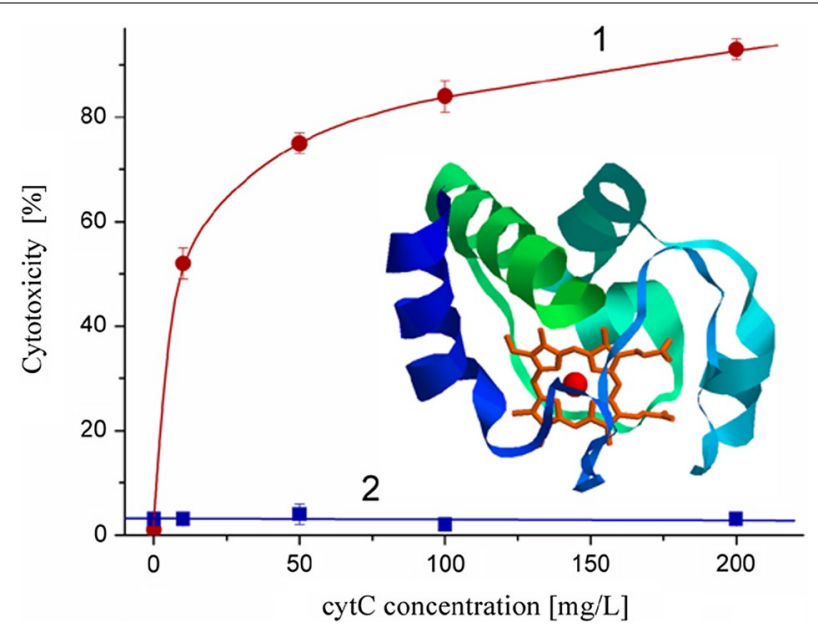

Fig. 6 Concentration dependence of the cytotoxic effects after $96 \mathrm{~h}$ treatment with suspension of cytC-MM composite particles (indicated by the protein concentration at constant 10:3 mg/mg cytC/MM ratio, curve 1) and with solution of cytC (line 2). Inset: model of cytC macromolecule obtained by visualization of the crystallographic coordinates (Protein data bank, 1HRC). The a-helix sections are presented as ribbons, the curves visualize the unspiral parts of the polypeptide chain; the haem is orange colored, and $\mathrm{Fe}^{3+}$-atom (in the center of the haem) is red

the size of cytC-MM particles above its optimal value; in this case the concentration dependence must show a maximum and a degressive part. Besides, particularly interesting is the form of the cytC-MM concentration dependence, because it can reveal how many factors determine the cytotoxic effect. Unlike the experiments with cytC adsorption and viability ("Aqueous cytC-MM suspension" and "Viability at presence of cytC, MM and cytC-MM" sections), to study the concentration dependence of the cytotoxicity we have begun with 20 times higher cytC-MM concentration retaining the optimal cytC/MM ratio.

Figure 6 shows that the cytotoxicity rapidly grows with the concentration of cytCMM particles but it appears a tendency to saturation at further increasing. The result discloses that the concentration of cytC-MM particles ( $10 \mathrm{mg} / \mathrm{L} \mathrm{cytC}, 3 \mathrm{mg} / \mathrm{L} \mathrm{MM})$ which have been chosen as optimal for adsorption (to avoid aggregation) leads to cytotoxic effect which is about $2 / 3$ of the maximal; as optimal can be chosen the protein concentration in the range $50-100 \mathrm{mg} / \mathrm{L}$ cytC at the same cytC/MM ratio.

\section{Discussion}

\section{CytC-MM particles}

The phagocytosis is conditioned by the possibility of the cytoplasmic membrane to form vesicles. The minimal and maximal size of a colloid particle subjected to uptake is determined by the mechanical properties of the membrane, which is determined by the module of elasticity of the lipid bilayer at bending and by the submembrane cytoskeleton. At smaller or larger size the membrane cannot enclasp the particle because of insufficient flexibility, or shortage of enough 'free' membrane area, respectively. 
To use particles with optimal size we have isolated fractions of the polydisperse MM suspension by fourfold differential centrifugation employing the early developed procedure (Hristova and Zhivkov 2015). It was chosen the fraction with mean size $B=0.46 \mu \mathrm{m}$ (determined by Eq. (3) from the measured relaxation time $\tau_{0}=5.9 \mathrm{~ms}$ ) which is near to the upper limit for active uptake $(0.5 \mu \mathrm{m}$, according to the literature data (Cortez et al. 2007)) to input maximal number of cytC globules into a cancer cell at phagocytosis of one cytC-MM particle.

The visualization of MM monoplates by electron microscopy is difficult because of their extremely small thickness: the electron density of a $1 \mathrm{~nm} \mathrm{Al}-\mathrm{Si}-\mathrm{O}$ plate does no allow obtaining TEM photos with satisfactory contrast. Such problems appear at all alumosilicate clays with symmetrical structure witch allow decomposition of their laminar packs down to monoplates. For such nanoparticles the most effective are the electrooptical methods: the size and polydispersity of 25-90 nm laponite nanoplates was determined by electric birefringence (Zhivkov and Stoylov 2002). In case of MM suspension with submicron nanoplates, the electric light scattering is more suitable due to its highest sensitivity to colloid particles with size commensurable to the wavelength.

To analyse the polydispersity the decay curve $\Delta I_{t}(t)$ of EOE was decomposed to monoexponents; to consider adequately the contribution of all fractions it was applied electric field with high strength (leading to high degree of particle orientation), and the field was switched off after reached steady-state EOE $\Delta I_{s}$. By that it was found out that EOE of the further used MM suspension can be considered as caused by three fractions of particles with relaxation time/size/share ( $\tau, B$, \%): (a) $39 \mathrm{~ms}, 0.87 \mu \mathrm{m}, 16 \%$; (b) $4.1 \mathrm{~ms}, 0.41 \mu \mathrm{m}$, $71 \%$; (c) $1.2 \mathrm{~ms}, 0.27 \mu \mathrm{m}, 13 \%$; this relatively narrow submicrometric size distribution is reached due to effective centrifuging of the strongly polydisperse original MM suspension containing nanoplates with micrometric size.

As a criterion for the size of $\mathrm{MM}$ and cytC-MM particles (which should strongly increase at aggregation) we use the relaxation time $\tau_{0} \sim 1 / 6 D_{\mathrm{r}}$ of disorientation after switching off the electric field; the method is very size-sensitive due to the cubic dependence of the rotational diffusion coefficient $D_{\mathrm{r}} \sim 1 / B^{3}$ on the size $B$, in difference form the linear size-dependence of the translational coefficient $D_{\mathrm{tr}} \sim 1 / B$ used in the dynamic light scattering (DLS). Besides the low sensitivity, the commercial devices for DLS give the particle size as equivalent sphere with diameter, which value is very inaccurate in case of particles with strongly asymmetrical form (the size/thickness ratio of the used MM pales is near to 500:1). The measured relaxation time $\tau_{0} \sim \eta B^{3} / k T$ of EOE is determined manly by the diameter $B$ of the MM plates; the decreasing of viscosity $\eta$ with the temperature $T$ (the $-\Delta \eta$ and $+\Delta T$ are caused by the electric current in the suspension) are negligible due to the very low conductivity and the short (a few milliseconds) electric impulse required to reach high degree steady-state orientation.

At saturated adsorption of the positively charged cytC globules on the negative $\mathrm{MM}$ nanoplates the composite cytC-MM particles pass over transient (time-dependent) zero charge state (analogical from the protein-concentration isoelectric point in Fig. 3) near which the van der Waals attraction predominates over the electrostatic repulsion; that conditions their aggregation. Therefore, to retain the optimal for phagocytosis $0.5 \mu \mathrm{m}$ size, we have found empirically the optimal concentration of the bare MM plates and optimized the time-dependent pouring of cytC solution into the MM suspension. The 
EOE results show out that the bare MM particles have $\tau_{0}=5.9 \mathrm{~ms}$ which corresponds to disk with diameter $B=464 \mathrm{~nm}$; and after cytC adsorption the relaxation time increases up to $\tau_{0}=7.5 \mathrm{~ms}$. This insignificant increment $\Delta \tau=1.6 \mathrm{~ms}$ reflects the additional friction caused by the protein globules adsorbed on the smooth MM surface, but it not manifests arising of aggregates. The absence of aggregation is proved by the facts that after completed saturated adsorption (10:3 $\mathrm{mg} / \mathrm{mg}$ cytC/MM ratio): (a) the relaxation curve $\Delta I_{\mathrm{t}}(t)$ does not show appearance of tail (an indication for large particles) (b) the relaxation time $\tau_{0}$ and the intensity of scattering $\left(I_{0}\right.$ at constant exciting light) does not increase for a several hours; and (c) the field-strength dependence $\tau_{0}(E)$ does not change its form (at low $E$ the electric field orients predominantly the large particles, the contribution of smaller ones increases with $E$ ). The absence of aggregation at passing the transient (time-dependent) zero-charge state can be explained by the enormous difference in the translation diffusion coefficients of the $3 \mathrm{~nm}$ cytC globules and $460 \mathrm{~nm} \mathrm{MM}$ plates, which leads to quick protein adsorption (and recharging from negative to positive charge) before the neighbour cytC-MM particles can approach enough to come into close contact due to attraction caused by the London dispersion forces.

The degree of finished adsorption at given concentration of cytC was determined by measuring the electrophoretic mobility $\mu$. The values of the electrokinetic potential $\zeta$ in Fig. 3 (calculated by Eq. (1) using Henry's function $f(a / \delta)$ for spherical particles with smooth surface) are rather semiquantitative than quantitative, because: (a) non-spherical form of MM plates and (b) increased surface friction caused by the adsorbed protein globules on the smooth MM surface; so, more reliable is the experimental quantity $\mu$. Nevertheless, we use $\zeta$ instead $\mu(\zeta, \eta, \varepsilon)$, because: (a) at considering the protein-concentration dependence of the adsorption it is enough to know the alteration of the total charge in relative units; and (b) the biologists are acquainted with $\zeta$, probably because it allows less comparison without considering the viscosity $\eta$ and dielectric permittivity $\varepsilon$ of the medium.

\section{Cytotoxicity}

The inducing of apoptosis by exogenous cytC imitates the mitochondrial path (Gupta 2003; Jiang and Wang 2004) which begins with outgoing of cytC from the mitochondria when their external membrane is damaged under action of physical (ultraviolet radiation) or chemical (free radical, etc.) agents. The introduction of cytC into cytoplasm starts a cascade of biochemical reactions which begins with electrostatic association of cytC with the protein Apoptotic protease-activating factor (Apaf-1); the cytC-Apaf-1 associates arise at overcoming of cytC concentration threshold which is estimated as $16 \mu \mathrm{m} \mathrm{cytC}$ in $150 \mathrm{MM} \mathrm{KCl}$ (Cain et al. 2001). Therefore, it is important to introduce maximal number of cytC macromolecules at uptake of one cytC-MM composite particle and to phagocyte a larger number of particles, according the formulated in "Introduction" requirements.

The experiment with microinjection of cytC (Zhivotovsky et al. 1998) shows out that the apoptosis in cancer cells can be started by introducing of exogenous cytC, but its adding as solution (with increasing concentration) to cancer cell culture does not influence noticeably the cell survivability (independently on the time of treatment) (Figs. 4 and 5); the result is expected taking into consideration the impossibility of water-soluble 
proteins to penetrate across the hydrophobic sublayer of the lipid membranes. We started the investigation supposing that it is possible to initiate the apoptosis by introducing of cytC as adsorbed on MM plates considering the possibility of the cancer cells to phagocytize colloid particles, but it was only hypothesis, because the two methods are quite different: by microinjection the cytC is introduced directly into the cytoplasm, and the phagocytized cytC-MM particle are enclosed in vesicle which membrane is impenetrable for cytC (the endosomal membrane is a part of former cytoplasmic one). The experiments have shown out that the cell viability deceases with the time at adding of suspension of previously prepared cytC-MM particles. Obviously the cytotoxic effect is caused by the composite particles, because the adding of suspension with bare MM particles give not effect (Figs. 4 and 5); the absence of cytotoxic effect corresponds to already proved non-toxicity of MM particles as nutritional supplement permitted by U.S. Food and drug administration (FDA). Further our investigations were aimed to formulate rules (given in "Introduction") for preparation of composite particles with high cytotoxicity; the present investigation was aimed mainly to find out optimal concentrations of cytC protein and MM plates.

The exploration of the literature have discovered earlier attempts to use composite nanoparticles with adsorbed cytC as anticancer agent (Malekigorji et al. 2014; Méndez, et al. 2014; Santra et al. 2010; Ng et al. 2013) but with low efficiency: the reached cytotoxicity is about $60 \%$, which does no allow considering this approach as competitive to that with the organic-molecular anticancer agents. We thing that the reason is that the authors have no applied colloid-chemistry approach to reach better efficiency: their efforts were aimed to synthesize sophisticated nanoparticles as carrier of cytC but not to investigate the protein adsorption on them.

The reached by us $95 \%$ cytotoxicity (after $96 \mathrm{~h}$ treatment with cytC-MM suspension) is drastically better in comparison with the obtained by other authors, although the comparison is not quite adequate because of testing on different cancer types, cell lines and cytC concentrations; nevertheless the difference of $1 / 3$ cytotoxicity is impressive. Our results mean an improvement over previous research due to: (a) choosing of appropriate colloid particles as carrier (MM has $\mathrm{pH}$-independent negative charge, plate-like form, high surface/mass ratio, and the used fraction with $0.5 \mu \mathrm{m}$ size is optimal for the phagocytosis); (b) the experimental conditions of cytC adsorption are optimized to reach high surface protein density ( $\mathrm{pH} 6$, where cytC globules are positively charged; the low ionic strength facilitate the electrostatic adsorption); (c) the cytC-MM particles at saturated protein adsorption are positively charged (that causes their electrostatic attraction to the negatively charged cytoplasmic membrane of the cancer cells). Figure 7 visualizes our understanding of a cytC-MM particle adsorbed on the cytoplasmic membrane.

We suppose that the intracell action of cytC is the limiting factor for the rate of the cytotoxic effect, the adsorption of cytC-MM particles on the cytoplasmic membrane is relatively quick. However, it remains unclear what happens with the cytC globules in the endosome and how they enter into the cytoplasm. A possible explanation is based on the fact that the permeability of the biological membrane drastically increases for macromolecules because of peroxide oxidation of its unsaturated lipids; the process is initiated by activated oxygen in the form of superoxide anion-radical $\mathrm{O}_{2}{ }^{-\cdot}$ and its products: perhydroxyl radical $\mathrm{HO}_{2}^{-}$, peroxide $\mathrm{H}_{2} \mathrm{O}_{2}$, hydroxyl-radical $\mathrm{HO}$. and singlet oxygen ${ }^{1} \mathrm{O}_{2}$, 


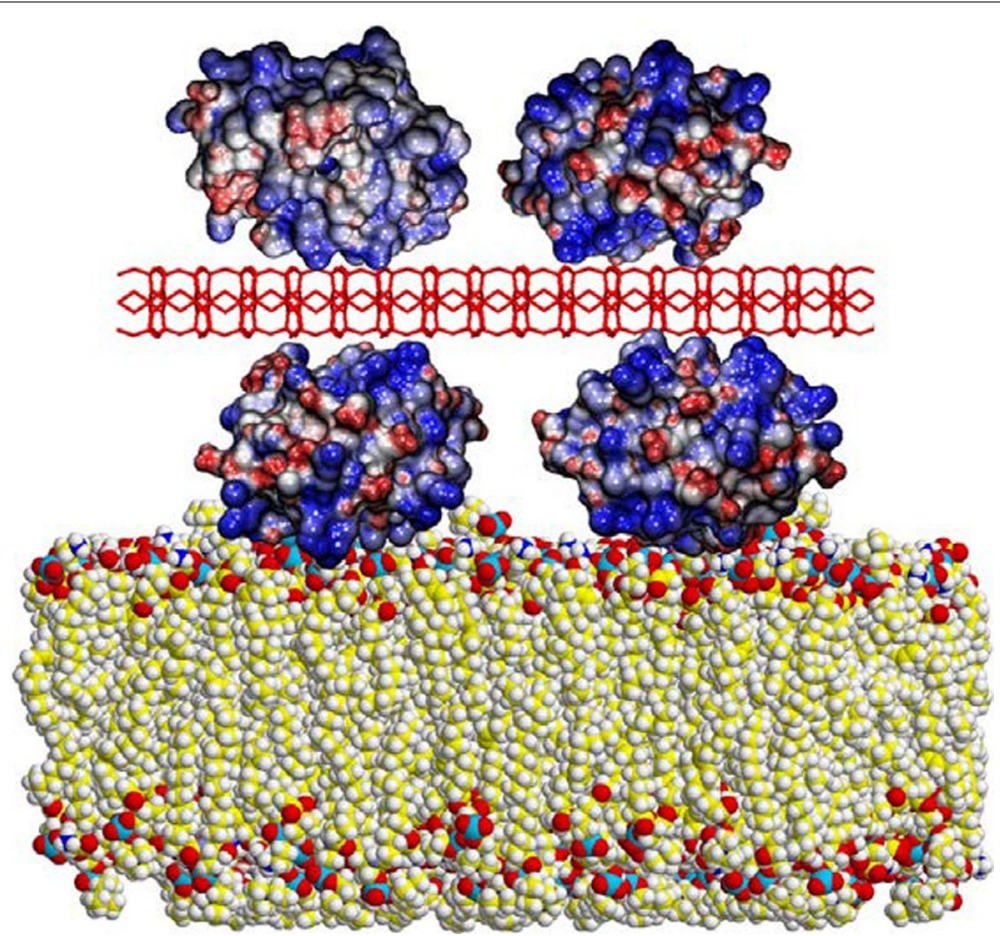

Fig. 7 Fragment of cytC-MM particle with 4 cytC globules (cross section), which is adsorbed on a phospholipid membrane (molecular-dynamic simulation, phosphatidylserine/phosphatidylcholine ratio 20:80). The MM nanoplate, the negative surface potential of the cytC globules and the oxygen atoms in the lipid heads are coloured in red, in difference from the nitrogen atoms and the positive potential which are blue coloured

which concentrations in the cytoplasm of cancer cells are strongly increased as result of the blocked oxidative phosphorylation, in contradiction to the normal cells, where the free radicals (normal intermediates in the process of one-electron reduction of the triplet oxygen ${ }^{3} \mathrm{O}_{2}$ to $\mathrm{H}_{2} \mathrm{O}$ ) do not exit out from the mitochondria. In particular, in presence of $\mathrm{H}_{2} \mathrm{O}_{2}$ (which concentration in the cancer cells is highly increased (LópezLázaro 2007; Szatrowski and Nathan 1991; Lennicke et al. 2015)) the oxidized cytC (with $\mathrm{Fe}^{3+}$-atom in the haem as the used in our experiment) initiate peroxide oxidation of the lipid membranes (Radi et al. 1991, 1993). We suppose that the exogenous cytC (introduced in the cell by phagocytosis of cytC-MM particles) percolates trough the damaged endosome membrane into cytoplasm, where it starts the process of apoptosis like cytC directly injected (Zhivotovsky et al. 1998). This hypothesis requires further investigations which must start with experimental disclosing of the mechanism leading to the cell death: apoptosis or necrosis.

We use equine cytC, because its low cost (in difference from human cytC) allows its application for therapy of human cancers. The alignment analysis reveals that the $3 \mathrm{D}$ structure of equine and human cytC is almost the same (the identity is 97\%) (Fig. 8); that predicts the same mechanism of cytotoxicity: apoptosis (as in vivo when the endogenous cytC exits from the mitochondria), although this supposition needs experimental verification. The high degree of structural identity and the low 


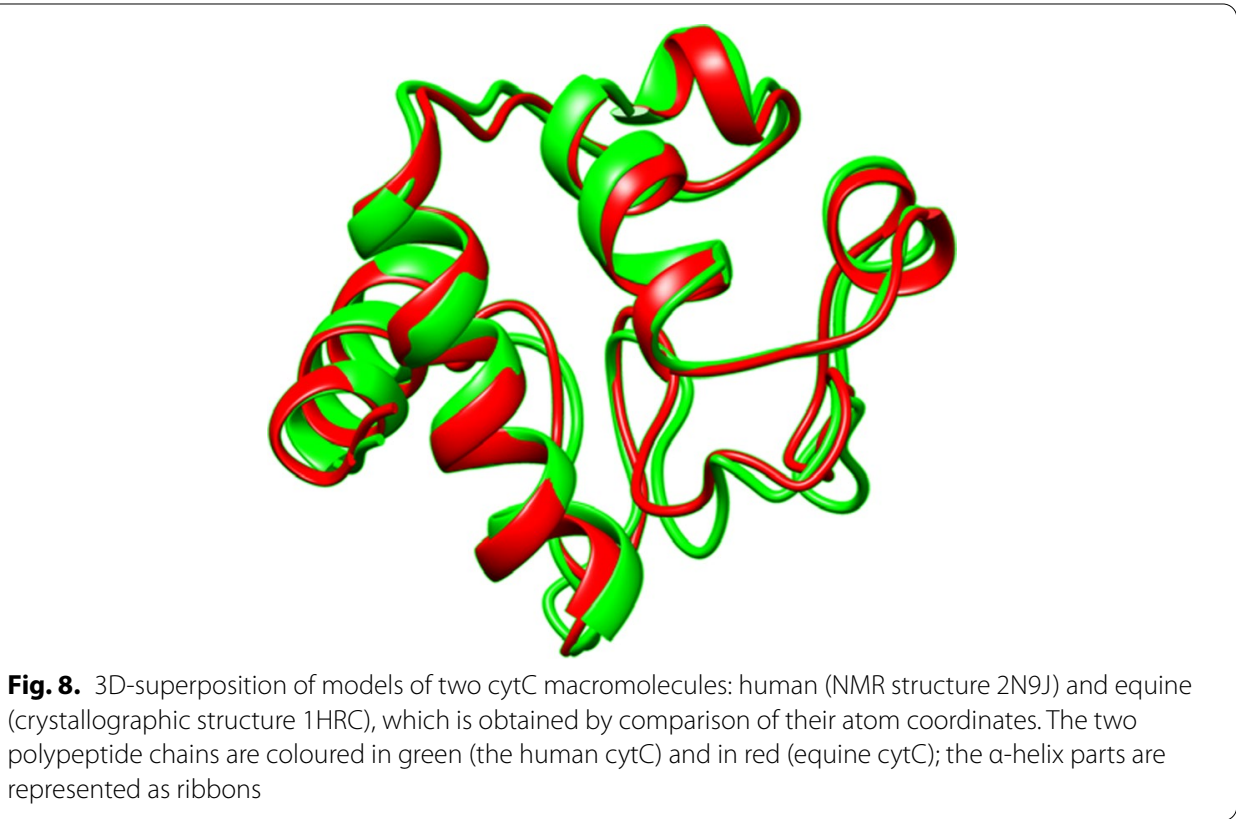

molecular mass of cytC macromolecules strongly decreases the probability for undesirable immune reactions.

The obtained high cytotoxicity opens the potentiality to apply cytC-MM suspension for direct treatment of the skin tumors or by peroral application in case of superficial neoplasms of the alimentary system (mouth cavity, esophagus, stomach, jejunum and colon), or by enema in the last case. The peroral treatment with suspension of cytCMM composite particles is possible due to the slow denaturation of the equine cytC (Kuroda et al. 1992) even at the low $\mathrm{pH}$ in the stomach.

For the potential application of cytC-MM particles in anticancer therapy it is very important that they do not damage the health cells of tissues surrounding the treated neoplasm. An expectation for that give the experiments: in vitro with cell cultures and in vivo with live mice, showing out that colloid particles with adsorbed cytC (Guo et al. 2021; Tang et al. 2014) or MM particles bearing anticancer medicaments (Taleblou et al. 2020; Akbal et al. 2018) cause death of cancer cells and destroy neoplasms but do not influences health cells and tissues. Although the authors do not explain the absence of effects on the normal cells, we suppose that it is due to the lost capability of the differentiated cells to phagocytize colloid particles. The experimental facts allow assuming that $\mathrm{MM}$ with adsorbed cytC will not have cytotoxic effect on the normal cells and health tissues.

\section{Conclusion}

The water-soluble globular haemoproteid cytochrome $c$ (cytC) leads to destruction of cancer cells if it is previously adsorbed on montmorillonite (MM) colloid monoplates which are used as cytC-carrier. To prepare cytC-MM composite particles with high cytotoxicity ten conditions should be satisfied, which determine requirements to the particle size, form and electric charge, the cytC adsorption $(\mathrm{pH}$, ionic strength 
and cytC/MM ratio) and the concentrations of $\mathrm{MM}$, cytC and cytC-MM suspensions; the rules are applicable to all types of nano- and colloid particles. The optimal is the neutral $\mathrm{pH} 6-8$, where $\mathrm{pH}$-dependence of the net charge of free cytC globules, calculated by protein electrostatics, has positive plateau which is the most appropriate for saturated electrostatic adsorption of the cytC globules on the negatively charged MM plates. In vitro experiments with colon cancer cell culture disclose that the optimal cytC/MM ratio is $10: 3 \mathrm{mg} / \mathrm{mg}$ of the weight concentrations. After $96 \mathrm{~h}$ treatment the cytotoxicity (percent of dead cancer cells) of cytC-MM composite particles riches $95 \%$ due to the found by us optimal conditions; this result is significantly better than the $60-65 \%$ reached by other authors using various particles, as described in the literature. The cytotoxicity rapidly increases with concentration of the cytC-MM particles but further it shows tendency to saturation.

\title{
Abbreviations
}

cytC: Cytochrome c; MM: Montmorillonite.

\section{Acknowledgements}

This work is supported by the Bulgarian Ministry of Education and Science under the National Program for research "Young Scientist and Postdoctoral Students". The Medical University-Sofia have supported S. Hristova as young researcher for publication in an open access journal.

\section{Authors' contributions}

AMZ: conceptualization, methodology, formal analysis, visualization: graphics, writing —original draft, writing —review and editing, supervision, project administration. SHH: investigations: physicochemical experiments, computer simulations and biological cell cultures; visualization: molecular models, resources; validation. All authors read and approved the final manuscript.

\begin{abstract}
Authors' information
Prof. Dr. Alexandar M. Zhivkov —Education: student on Medical University-Sofia (1976-1980), then has finished "Molecular biology" and MS degree in "Biophysics" at Faculty of Biology, Sofia University (1980-1984), MSc. thesis: "Spectrophotometric setup for electric dichroism" (1984). Postgraduate specializations: Departure of Physicochemical Biology, Moscow State University "Lomonosov" (1985-1987), and Institute of Biophysics (Pushtino, Moscow region, Russian Academy of Science) (1988-1990); Ph.D. Thesis: "Optical and electro-optical investigations of purple membranes" (Sofia, 1996); Employments: Institute of Electronics (Bulgarian Academy of Sciences, BAS) and (since 1992) Institute of Physical Chemistry (BAS), Associate Professor since 2004. Short-term working visits: Iowa State University (lowa City, USA, 20022004 annually), Frumkin Institute of Physical Chemistry (Russian Academies of Sciences, Moscow, 1999-2011, annually); University of Ghent (Belgium, 2011-2013 annually); Tokyo University (2006); University of Franche-Comte (Besancon, France, 2007); Technical University (Berlin, 2010); University of San Francisco (USA, 2014). Dr. Svetlana H. HristovaEducation: Sofia University "St. Kliment Ohridski", Faculty of Biology, Bachelor's degree: "Molecular biology", 2002-2006; Sofia University "St. Kliment Ohridski", Faculty of Biology, Master's degree: "Biophysics" 2006-2008. Doctorate-Chemical sciences: Institute of physical chemistry, Bulgarian Academy of Sciences, (BAS), Sofia, Department "Interfaces and Colloids", 2008-2009 and 2012-2014. Ph.D. Thesis: "Electric properties and anticancer effect of cytochrome c adsorbed on colloid particles from montmorillonite, Institute of physical chemistry, BAS, Date of acquire: 20.06.2019. Employments: (1) National specialized hospital for active treatment of haematological diseases, Sofia, Laboratory “Hematopoietic stem cell transplantation and cellular therapies", biologist, 2009-2019; (2) Institute of Physical Chemistry, Bulgarian Academy of Sciences (BAS), Department "Interfaces and Colloids", physicist, 2014-2019; (3) Medical University-Sofia, Medical faculty, Department of medical physics and biophysics, assistant professor, since 2019 till now.
\end{abstract}

\section{Funding}

The research is supported by postdoctoral grant from the Bulgarian Ministry of Education for Svetlana Hristova as a young scientist, it gives some rise to her month salary as a teacher at the Department of medical physics and biophysics (Medical University-Sofia); the grant has no a number as a regular research project. The Medical University-Sofia have supported S. Hristova as assistant professor for publication in an open access journal.

Availability of data and materials

Not applicable.

\section{Declarations}

Ethics approval and consent to participate

Not applicable.

\section{Consent for publication}

Not applicable. 


\section{Competing interests}

The authors declare that they have no conflicts of interest and/or competing interests.

\section{Author details}

${ }^{1}$ Department of Medical Physics and Biophysics, Medical Faculty, Medical University-Sofia, Zdrave Str. 2, 1431 Sofia, Bulgaria. ${ }^{2}$ Rostislaw Kaishew" Institute of Physical Chemistry, Bulgarian Academy of Sciences (BAS), Acad. G. Bonchev Str., bl. 11, 1113 Sofia, Bulgaria.

Received: 2 June 2021 Accepted: 9 August 2021

Published online: 23 August 2021

\section{References}

Akbal O, Vural T, Malekghasemi S, Bozdoğan B, Denkbaş EB (2018) Saponin loaded montmorillonite-human serum albumin nanocomposites as drug delivery system in colorectal cancer therapy. Appl Clay Sci 166:214-222

Bhattacharya B, MohdOmar MF, Soong R (2016) The Warburg effect and drug resistance. Br J Pharmacol 173:970-979

Cain K, Langlais C, Sun XM, Brown DG, Cohen GM (2001) Physiological concentrations of K+ inhibit cytochrome c-dependent formation of the apoptosome. J Biol Chem 276:41985-41990

Cortez C, Tomaskovic-Crook E, Johnston APR, Scott AM, Nice EC, Heath JK, Caruso F (2007) Influence of size, surface, cell line, and kinetic properties on the specific binding of A33 antigen-targeted multilayered particles and capsules to colorectal cancer cells. ACS Nano 1:93-102

Dickerson RE, Timkovich R (1975) 7 Cytochromes c. Enzymes 11:397-547. https://doi.org/10.1016/S1874-6047(08)60215-2 Dukhin SS, Deryagin BV (1976) Electrophoresis. Nauka

El-Hamshary H, El-Newehy MH, Mohideen M, El-Faham A, Elsherbiny AS (2019) Evaluation of clay-ionene nanocomposite carriers for controlled drug delivery: synthesis, in vitro drug release, and kinetics. Mater Chem Phys 225:122-132

Endo S, Nagayama K, Wada A (1985) Probing stability and dynamics of proteins by protease digestion I: comparison of protease susceptibility and thermal stability of cytochrome c. J Biomol Struct Dyn 3:409-421

Gatenby RA, Gillies RJ (2004) Why do cancers have high aerobic glycolysis. Nature Rev Cancer 4:891-899

Gennis RB (1989) Biomembranes: molecular structure and function. Springer Science \& Business Media, Berlin

Gogvadze V, Orrenius S, Zhivotovsky B (2009) Mitochondria as targets for cancer chemotherapy. Semin Cancer Biol 19:57-66

Green DR, Reed JC (1998) Mitochondria and apoptosis. Science 281:1309-1312

Guo C, Zhang Y, Li Y, Zhang L, Jiang H, Tao J, Zhu J (2021) Gold nanoparticle-guarded large-pore mesoporous silica nanocomposites for delivery and controlled release of cytochrome c. J Coll Interface Sci 589:34-44

Gupta S (2003) Molecular signaling in death receptor and mitochondrial pathways of apoptosis. Intern J Oncol 22:15-20

Hristova SH (2019) Electric properties and anticancer effect of cytochrome $c$ adsorbed on colloid particles from montmorillonite. Ph.D. thesis, Institute of Physical Chemistry, Bulgarian Academy of Sciences, Sofia

Hristova SH, Zhivkov AM (2015) Adsorption of cytochrome c on montmorillonite nanoplates: protein concentration dependence. J Colloid Interface Sci 446:252-262

Hristova SH, Zhivkov AM (2019a) Cytotoxic effect of exogenous cytochrome c adsorbed on montmorillonite colloid particles on colon cancer cell culture. Compt Rend Acad Bulg Sci 72(2):198-203

Hristova SH, Zhivkov AM (2019b) Isoelectric point of free and adsorbed cytochrome $c$ determined by various methods. Colloids Surf B Biointerfaces 174:87-94

Hristova SH, Zhivkov AM (2019c) Electrooptical determination of the isoelectric point of globular proteins: cytochrome $c$ adsorbed on montmorillonite nanoplates. Colloids Surf B 176:480-487

Hristova SV, Zhivkov A, Atanasov B (2009) Electrostatics of horse heart cytochrome $c$ and montmorillonite monolamellar plate. Biotechnol Biotechnol Equip 23(sup.1):568-571

Hunter RJ (1981) Zeta potential in colloid science. Academic press, London

Jafarbeglou M, Abdouss M, Shoushtari AM, Jafarbeglou M (2016) Clay nanocomposites as engineered drug delivery systems. RSC Adv 6:50002-50016

Jayrajsinh S, Shankar G, Agrawal YK, Bakre L (2017) Montmorillonite nanoclay as a multifaceted drug-delivery carrier. J Drug Deliv Sci Technol 39:200-209

Jiang X, Wang X (2004) Cytochrome c-mediated apoptosis. Ann Rev Biochem 73:87-106

Kandasamy K, Srinivasula SM, Alnemri ES, Thompson CB, Korsmeyer SJ et al (2003) Involvement of proapoptotic molecules bax and bak in tumor necrosis factor-related apoptosis-inducing ligand (TRAIL)-induced mitochondrial disruption and apoptosis: differential regulation of cytochrome $c$ and Smac/DIABLO release. Can Res 63:1712-1721

Kantardjiev AA, Atanasov BP (2009) PHEMTO: protein pH-dependent electric moment tools. Nucleic Acids Res 37:W422-W427

Karataş D, Tekin A, Bahadori F, Çelik MS (2017) Interaction of curcumin in a drug delivery system including a composite with poly (lactic-co-glycolic acid) and montmorillonite: a density functional theory and molecular dynamics study. J Mater Chem B 5:8070-8082

Khatoon N, Chu MQ, Zhou CH (2020) Nanoclay-based drug delivery systems and their therapeutic potentials. J Mater Chem B 8:7335-7351

Krupskaya WV, Zakusin SV, Tyupina EA, Dorzhieva OV, Zhukhlistov AP, Belousov PE, Timofeeva MN (2017) Experimental study of montmorillonite structure and transformation of its properties under treatment with inorganic acid solutions. Minerals 7:49

Kuroda Y, Kidokoro SI, Wada A (1992) Thermodynamic characterization of cytochrome $c$ at low pH: observation of the molten globule state and of the cold denaturation process. J Mol Biol 223:1139-1153

Lee CH, Lang J, Yen CW, Shih PC, Lin TS, Mou CY (2005) Enhancing stability and oxidation activity of cytochrome c by immobilization in the nanochannels of mesoporous aluminosilicates. J Phys Chem B 109:12277-12286 
Lennicke C, Rahn J, Lichtenfels R, Wessjohann LA, Seliger B (2015) Hydrogen peroxide-production, fate and role in redox signaling of tumor cells. Cell Commun Signaling 13:1-19

Leporatti S, Mariafrancesca C, De Matteis V, Rinaldi R (2020) Design of nano-clays for drug delivery and bio-imaging: can toxicity be an issue? Nanomedicine 15:2429-2432

Liao J, Peng S, Long M, Zhang Y, Yang H, Zhang Y, Huang J (2020) Nano-Bio interactions of clay nanotubes with colon cancer cells. Colloids Surf A Physicochem Eng Asp 586:124242

López-Lázaro M (2007) Dual role of hydrogen peroxide in cancer: possible relevance to cancer chemoprevention and therapy. Cancer Lett 252:1-8

Maeda Y, Yamamoto H, Kitano H (1995) Self-assembled monolayers as novel biomembrane mimetics. 1. Characterization of cytochrome $\mathrm{c}$ bound to self-assembled monolayers on silver by surface-enhanced resonance Raman spectroscopy. J Phys Chem 99:4837-4841

Malekigorji M, Hoskins C, Curtis T, Varbiro G (2014) Enhancement of the cytotoxic effect of anticancer agent by cytochrome c functionalized hybrid nano-particles in hepatocellular cancer cells. J Nanomed Res 1:1-8

Méndez J, Morales Cruz M, Delgado Y, Figueroa CM, Orellano EA et al (2014) Delivery of chemically glycosylated cytochrome $c$ immobilized in mesoporous silica nanoparticles induces apoptosis in HeLa cancer cells. Mol Pharm 11:102-111

Murray HH (2006) 2D-structure and composition of the clay minerals and their physical and chemical properties. Developments in clay science. Elsevier, Amsterdam, pp 7-31

Nadeau PH (1985) The physical dimensions of fundamental clay particles. Clay Miner 20:499-514

Ng DYW, Fahrer J, Wu Y, Eisele K, Kuan SL, Barth H, Weil T (2013) Efficient delivery of p53 and cytochrome $c$ by supramolecular assembly of a dendritic multi-domain delivery system. Adv Healthc Mater 2:1620-1629

Paul KG (1948) The stability of cytochrome $c$ at extreme pH values. Acta Chem Scand 10:430-439

Persano F, Batasheva S, Fakhrullina Gl, Gigli G, Leporatti S, Fakhrullin RF (2021) Recent advances in the design of inorganic and nano-clays particles for the treatment of brain disorders. J Mater Chem B 9(12):2756-2784

Radi R, Turrens JF, Freeman BA (1991) Cytochrome $c$-catalyzed membrane lipid peroxidation by hydrogen peroxide. Arch Biochem Biophys 288:118-125

Radi R, Sims S, Cassina A, Turrens JF (1993) Roles of catalase and cytochrome $c$ in hydroperoxide-dependent lipid peroxidation and chemiluminescence in rat heart and kidney mitochondria. Free Radic Biol Med 15:653-659

Santra S, Kaittanis C, Perez JM (2010) Cytochrome c encapsulating theranostic nanoparticles: a novel bifunctional system for targeted delivery of therapeutic membrane-impermeable proteins to tumors and imaging of cancer therapy. Mol Pharm 7:1209-1222

Schoonheydt RA, Johnston CT, Bergaya F (2018) Clay minerals and their surfaces. In: Schoonheydt R, Johnston CT, Bergaya $F$ (eds) Developments in clay science. Elsevier, Amsterdam, pp 1-21

Shainberg I, Otoh H (1968) Size and shape of montmorillonite particles saturated with $\mathrm{Na} / \mathrm{Ca}$ ions (inferred from viscosity and optical measurements). Israel J Chem 6:251-259

Shannon AM, Bouchier-Hayes DJ, Condron CM, Toomey D (2003) Tumour hypoxia, chemotherapeutic resistance and hypoxia-related therapies. Cancer Treat Rev 29:297-307

Sharma B, Kanwar SS (2018) Phosphatidylserine: a cancer cell targeting biomarker. Seminars in cancer biology, vol 52. Academic Press, London, pp 17-25

Spartakov AA, Trusov AA, Voitylov AV, Vojtylov VV (2007) Electro-optics of polydisperse colloids. In: Stoylov SP, Stoimenova MV (eds) Molecular and colloid electro-optics. Taylor \& Francis, New York

Stoylov SP (1991) Colloid electro-optics - theory, techniques, applications. Academic Press, London

Szatrowski TP, Nathan CF (1991) Production of large amounts of hydrogen peroxide by human tumor cells. Can Res 51:794-798

Taleblou N, Sirousazar M, Hassan ZM, Khaligh SG (2020) Capecitabine-loaded anti-cancer nanocomposite hydrogel drug delivery systems: in vitro and in vivo efficacy against the 4T1 murine breast cancer cells. J Biomater Sci Polym Ed 31:72-92

Tang Y, Teng Z, Liu Y, Tian Y, Sun J, Wang S, Wang C, Wang J, Lu G (2014) Cytochrome C capped mesoporous silica nanocarriers for $\mathrm{pH}$-sensitive and sustained drug release. J Mat Chem B 2:356-4362

Vander Heiden MG, Cantley LC, Thompson CB (2009) Understanding the Warburg effect: the metabolic requirements of cell proliferation. Science 324:1029-1033

Vaughn AE, Deshmukh M (2008) Glucose metabolism inhibits apoptosis in neurons and cancer cells by redox inactivation of cytochrome c. Nat Cell Biol 10:1477-1483

Warburg O, Wind F, Negelein E (1926) Über den stoffwechsel von Tumoren im Körper. Klin Wochenschr 5:829-832

Whalley WR, Mullins CE (1991) Effect of saturating cation on tactoid size distribution in bentonite suspensions. Clay Miner 26:11-17

Win KY, Feng SS (2005) Effects of particle size and surface coating on cellular uptake of polymeric nanoparticles for oral delivery of anticancer drugs. Biomaterials 26:2713-2722

Yu M, Pan L, Sun L, Li J, Shang J, Zhang S, Liu D, LiW (2015) Supramolecular assemblies constructed from $\beta$-cyclodextrinmodified montmorillonite nanosheets as carriers for 5-fluorouracil. J Mater Chem B 3:9043-9052

Zhivkov AM (2007) Geometry of purple membranes in aqueous medium. In: Stoylov SP, Stoimenova MV (eds) Molecular and colloidal electro-optics. CRC, Taylor \& Francis, Boca Raton, pp 327-365

Zhivkov AM, Stoylov SP (2002) Electro-optical characterization of aqueous laponite suspensions. Colloids Surf A Physicochem Eng Aspects 209:315-318

Zhivotovsky B, Brustugun OT, Døskeland SO (1998) Injected cytochrome c induces apoptosis. Nature 391:449-450

\section{Publisher's Note}

Springer Nature remains neutral with regard to jurisdictional claims in published maps and institutional affiliations. 